\title{
Construction and Implementation of Teaching Mode for Digital Mapping based on Interactive Micro-course Technology
}

\author{
https://doi.org/10.3991/ijet.v13i02.8317 \\ Ning Gao \\ Henan University of Urban Construction, Pingdingshan, China \\ gaoninghaoyune 163.com
}

\begin{abstract}
The era of "Internet + education" has caused reforms in teaching ideas, teaching modes, and learning styles. The emergence of micro-course technology provides new strategies for integrating learning styles. Task-driven digital mapping teaching, known as traditional classroom organization, has poor teaching effect due to single learning style and strategy. A new teaching mode for digital mapping was constructed in this study based on micro-course technology by combining interactive micro-course technology and digital mapping teaching to adapt to the demands of modern teaching. This teaching mode mainly included four modules, namely, micro-courseware, micro-video, microexercise, and micro-examination. It realized the hierarchical teaching of knowledge points in digital mapping course, simplification of basic principles, simulation of engineering cases, and self-evaluation of learning outcomes. The teaching mode was applied to 114 students from the Mapping Engineering Department of Henan University of Urban Construction. Results indicate that the proposed teaching mode based on interactive micro-course technology promoting the independent after-class learning of the students, stimulating their learning enthusiasm, enhancing their practical abilities of the students, and improving the effect of teaching. This mode of teaching provides a new concept for the teaching mode reform of other courses in mapping engineering.
\end{abstract}

Keywords - interaction, micro-course, digital mapping, teaching mode

\section{Introduction}

Micro-learning has been gradually introduced into the lives of people in recent years given the popularization of informationized education and the rapid development of the Internet. As an effective resource for micro-learning, micro-course is highly appreciated by learners [1]. Micro-course is a short and incisive network video teaching course with flexible and free learning styles. It uses micro-teaching video as the major carrier and is mainly designed for specific knowledge points or teaching nodes of courses. The development of micro-course expands the connotation and denotation of traditional teaching mode. It is the key of teaching mode reform in universities and colleges at present [2] [3]. 
Digital mapping is an important course in mapping engineering. It plays the basic role in undergraduate teaching and lays the foundation for deep learning and study of mapping engineering. Currently, digital mapping mainly adopts the traditional mode of teaching, that is, teaching-demonstration-exercise, in many universities and colleges. However, this traditional mode of teaching has the following limitations. Relative simple teaching mode cannot sufficiently meet the demands of modern classroom teaching. Moreover, in this mode, teachers are the center in teaching activities, whereas students play a passive role in learning. Digital mapping neglects the subjective role of students and lacks interaction [4] [5]. Therefore, designing, developing, and applying interactive micro-course into teaching of digital mapping is an important research topic.

\section{State of art}

The concept of micro-course was developed by Penrose from San Juan College in New Mexico. This concept laid the foundation for the development of the microcourse theory. Recently, many educational institutions have begun to exert great efforts in the design and development of micro-video teaching. The most well-known is that of Salman Khan, founder of Khan Academy and launched a number of online video courses that offer free, high-quality network learning resources to learners around the whole world [1]. Moreover, the development of online teaching using micro-video has allowed educational scholars to further explore the application of micro-video in classroom teaching, including the realization of independent learning of learners by using micro-video in teaching during reform of classroom teaching mode.

Relatively, micro-course began late in China, and relevant studies have been reported. Liang is one of the early scholars who studied micro-course in China. He was the first Chinese to propose and believe that the concept of micro-course would surely become a new mode of teaching and learning style [6]. Moreover, Xie discussed the characteristics of interactive teaching using micro-video and system model and summarized the advantages of this mode of teaching through a contrastive analysis between interactive teaching using micro-video and video demonstration lessons [7]. Jin presented the construction of connotation of a main course system for different majors based on interactive micro-course [8]. The aforementioned research achievements suggest that existing studies on micro-course teaching in the world still have some shortcomings. (1) Given that Chinese studies on micro-course began late, most of the existing studies have focused on concept, meaning, feature, and other superficial discussions of micro-course but rarely involved its design and application. (2) Existing studies on micro-course mainly focus on videos but neglects the subjective role of students and lacks interaction. Thus, interaction in micro-course must be improved further. (3) To some extent, micro-course is applicable to teaching studies [9]. It is suitable to studies with simple concepts but needs further investigation when applied to complicated courses. 
In the present work, a teaching mode for digital mapping is constructed based on interactive micro-course technology by combining interactive micro-course technology and digital mapping teaching. This mode of teaching mainly includes four modules, namely, micro-courseware, micro-video, micro-exercise, and microexamination. It realizes the hierarchical teaching of knowledge points in digital mapping course, simplification of basic principles, simulation of engineering cases, and self-evaluation of learning outcomes.

\section{Construction of the teaching mode for digital mapping based on interactive micro-course}

On the basis of interactive micro-course and knowledge points in digital mapping course, a teaching mode for digital mapping based on interactive micro-course technology should include the core elements, namely, survey and analysis, design of interactive micro-course, and evaluation. The teaching mode for digital mapping based on interactive micro-course is shown in Fig. 1.

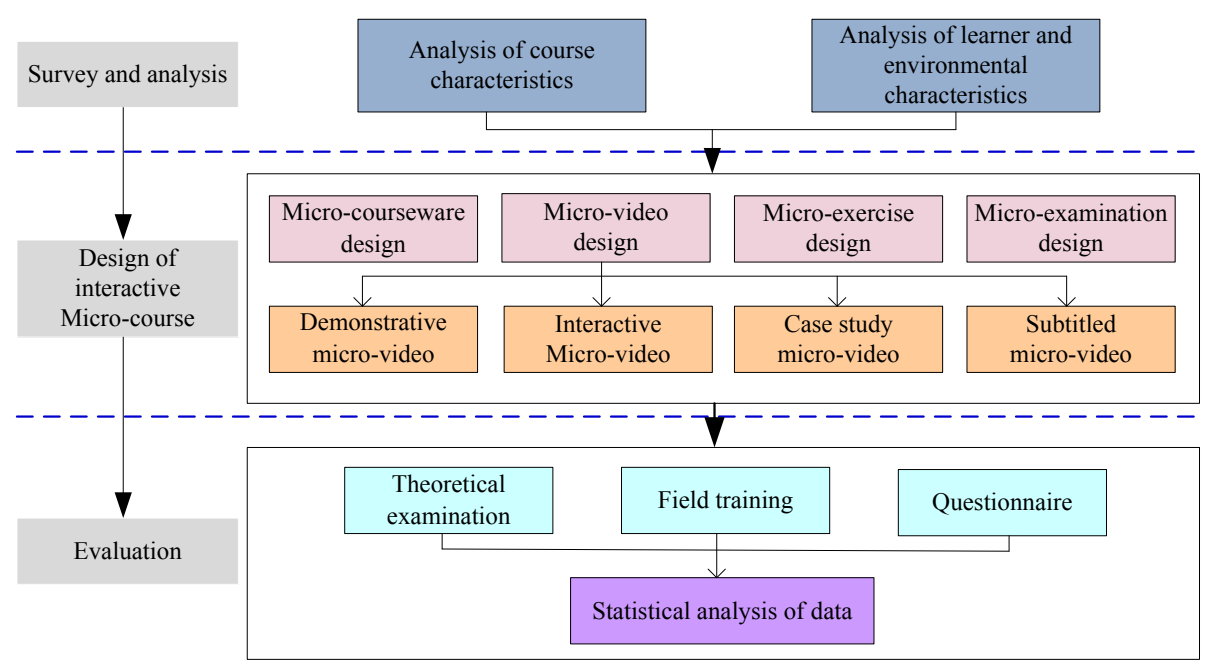

Fig. 1. The teaching mode for digital mapping based on interactive micro-course

\subsection{Survey and analysis}

Analysis of course characteristics. The digital mapping program in Henan University of Urban Construction includes theory teaching, classroom experiment, and production internship. This course focuses at large-scale digital mapping and introduces its principle, method, and applications comprehensively based on the elaboration of basic principles, basic theories, and measurement methods of surveying. The teaching content emphasizes on the integration of theories and practices and involves 
an extensive scope of knowledge and application fields [10]. In view of course contents, the characteristics of digital mapping are manifested in two aspects.

Strong logicality in formula derivation. For example, distance measurement by using phase method calculates distance according to the phase changes of continuous sinusoidal signals emitted by the total station instrument during reciprocal propagation on the measured distance. The calculation is as follows.

Sinusoidal signals of the total station instrument,

$$
u=V_{m} \sin \left(\omega t+\varphi_{0}\right)
$$

Where $V_{m}$ denotes the amplitude, $\omega$ is the angular frequency, $t$ represents time, and $\varphi_{0}$ is the initial phase.

Phase at emission,

$$
\Phi_{1}=\omega t_{0}+\varphi_{0}
$$

Phase at reception,

$$
\Phi_{2}=\omega t_{0}+\varphi_{0}+2 \omega t_{D}
$$

Phase difference,

$$
\Delta \Phi=\Phi_{2}-\Phi_{1}=2 \omega t_{D}
$$

Therefore,

$$
t_{2 D}=2 t_{D}=\frac{\Delta \Phi}{\omega}
$$

Combining with $D=\frac{1}{2} \cdot v \cdot t_{2 D}$, yields

$$
D=\frac{1}{2 \omega} \cdot v \cdot \Delta \Phi
$$

In addition, given

$$
\begin{gathered}
\omega=2 \pi f \\
v=\frac{c}{n}
\end{gathered}
$$

And

$$
\Delta \Phi=N \cdot 2 \pi+\Delta \varphi
$$

The distance measurement formula of the phase method is

$$
D=\frac{c}{4 \pi f n}(N \cdot 2 \pi+\Delta \varphi)
$$

Strong practicality. In traditional teaching method, teachers are mainly responsible for teaching theories and demonstrating operations, which mainly focuses on imitation. The application of interactive micro-course technology can make intuitive micro-video or micro-courseware, such as operation of surveying instruments, threedimensional coordinates collection, topographic control surveys, total station instrument-based digital mapping data collection, and software mapping. Such teaching 
mode allows students to have interactive operational learning during and after class, thereby stimulating their learning enthusiasm and learning efficiency [11] [12].

Analysis of learner and environmental characteristics. Most students of digital mapping course major in mapping engineering. Students are generally good at operation. According to a class survey, $100 \%$ of the students have smart phones, and $92 \%$ of the students have laptop or computers. Most of these students are willing to have contact with live video, micro-video, and other network resources. Moreover, Henan University of Urban Construction basically completed campus informatization and digitalization with a wireless network that covered the entire university. Through this development, students can connect their mobile devices to the Internet at any time and place within the campus.

\subsection{Design principle of interactive micro-course}

Learning on micro-course is mainly an independent learning behavior of learners. The course design shall focus on the subjectivity of students and guiding role of teachers and follow the following principles to achieve a satisfying effect of learning.

1. Explicit objective and content integrity. The design of micro-course shall include explicit learning objective and complete teaching design. It shall divide the entire course content into small knowledge modules that gradually extend and form a series of connected hierarchical micro-courses.

2. Interaction. The one-way propagation of traditional teaching mode changes and interactive teaching is realized, thereby transforming the learning style of learners from passive to active. The design shall create learning scenarios and interaction links, and provide corresponding tasks, interaction questions, interaction simulation training, and evaluation test, except for teaching using micro-video.

3. Practicability. Digital mapping is a course with strong practicability. After mastering the basic theoretical knowledge of the course, learners shall operate surveying instruments to combine theoretical knowledge and practical content. Therefore, attention shall be paid to practical application during the design of interactive microvideo.

\subsection{Design of interactive micro-course}

The interactive micro-course mainly has four modules, namely, micro-courseware, micro-video, micro-exercise and micro-examination.

Micro-courseware design. Interactive micro-course guides students toward independent learning, that is, knowing their learning objective and task and applying the knowledge points they have learned. Therefore, the design of micro-courseware shall cover micro-course subjects, learning objective, learned knowledge points, and hierarchical relationships of knowledge points. For example, distance measurement by using the phase method is an important knowledge point in digital mapping and requires students to master the distance measurement principle of total station instrument. It involves electromagnetism, physics, and other theories. Moreover, many 
formulas and strong logics are involved. Hence, a micro-courseware for distance measurement is created based on phase method to display the deduction process of mathematical expressions thoroughly, as shown in Fig. 2.

Moreover, some abstract and difficult principle knowledge points are transformed in digital mapping into vivid and beautiful animations by using two-dimensional animation manufacturing software and attached with lively interpretation and texts. An animation micro-courseware is designed. The micro-courseware for quick, short-step measurement principle by using the polar coordinate method is shown in Fig. 3.

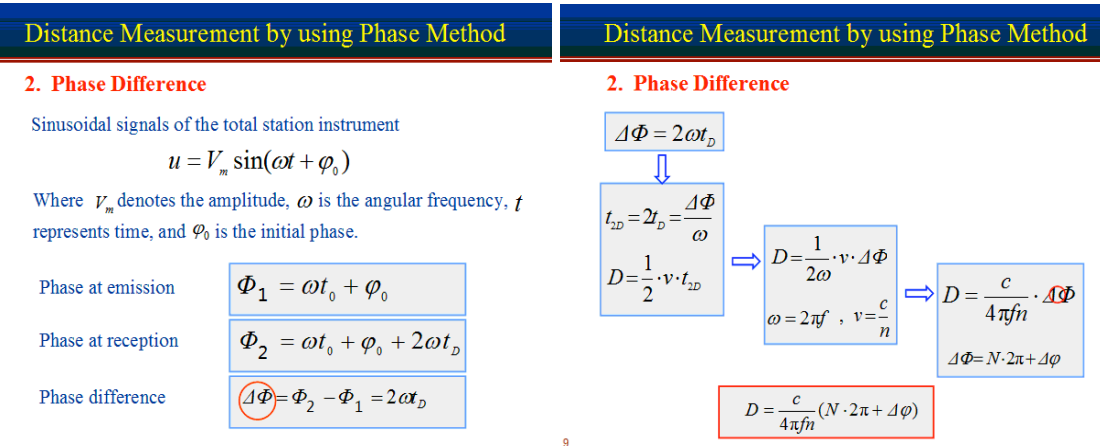

Fig. 2. Micro-courseware of distance measurement based on phase method

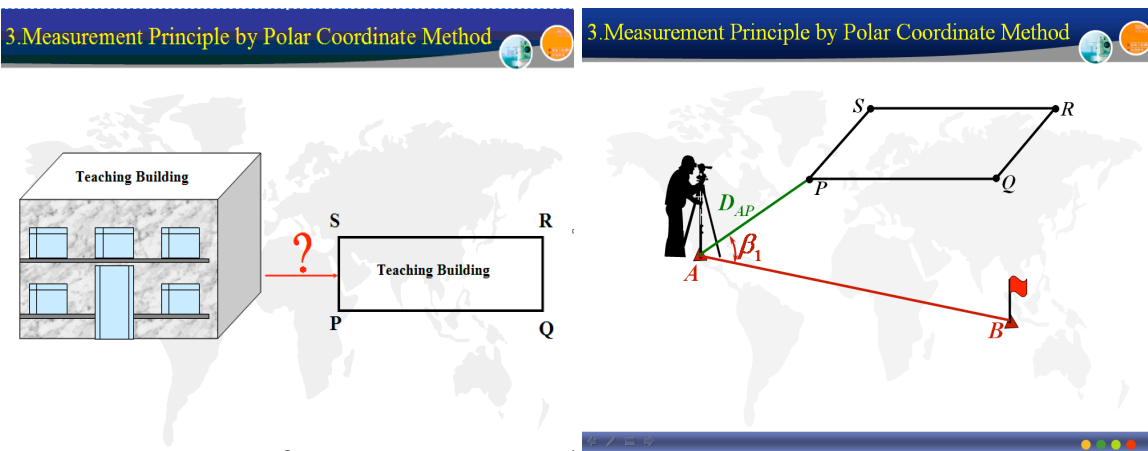

Fig. 3. Micro-courseware of measurement principle by polar coordinate method

\section{Micro-video design}

Demonstrative micro-video. Topographic data acquisition by using total station instrument is an important knowledge point in digital mapping. It mainly includes centering leveling of instrument, input and orientation of station data, and data acquisition of topographic characteristic points. The input and orientation of station data will directly influence the accuracy of data acquisition in the late period. Hence, a demonstration teaching video of the Reid and South total station instrument is created, as shown in Fig. 4. 

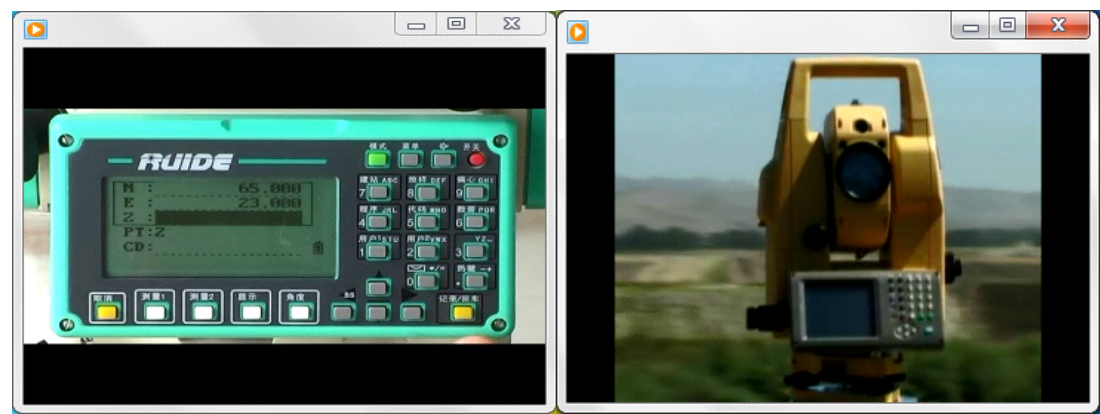

Fig. 4. Micro-video demonstration of the operation of total station instruments

Interactive micro-video. The teaching mode of simulation theoretical teaching and practices, interactive penetration, and gradual advancing is adopted for knowledge points that combine theories and practices in digital mapping [13]. The teaching mode that combines teaching and demonstration is applied in making the micro-video. For the convenience of interaction, two functions are applied to realize interactive microvideo. The first function is the bullet screen of the video. Here, students could discuss and express evaluations to specific contents in the video in real time while teachers could make further analysis and interpretation according to these comments to solve existing problems timely. The second function is the insertion of corresponding examination questions in the middle of the micro-video to test the mastery of learners regarding previous contents. For example, the micro-videos of large-scale topographic field data acquisition applied the point measurement method, the collection of quick, short step points, and the drawing of surface features at proper nodes, except for the bullet screen, by using a total station instrument and South field survey drafting of topographic map.

Case study micro-video. Production internship is an important part in the teaching mode of digital mapping. Students have to practice in an actual engineering environment. Therefore, micro-video shall be combined with actual engineering in specific production unit so learners can combine the technologies and specific engineering that they have learned, such as digital mapping tasks for the municipal administration building in the new urban district of Pingdingshan (Henan Province), Xiangyun Park, Baiguishan Reservoir National Wetland Park, closely through the learning of the micro-video, as shown in Fig. 5.

Subtitled micro-video. Subtitle is often added in micro-videos, except for corresponding teaching contents, such as opening subtitle, middle prompt texts, and end subtitle. The opening subtitle is often used to display topic information and key points of the micro-course, such as data acquisition by total station instrument. A subtitled micro-video is shown in Fig. 6. 


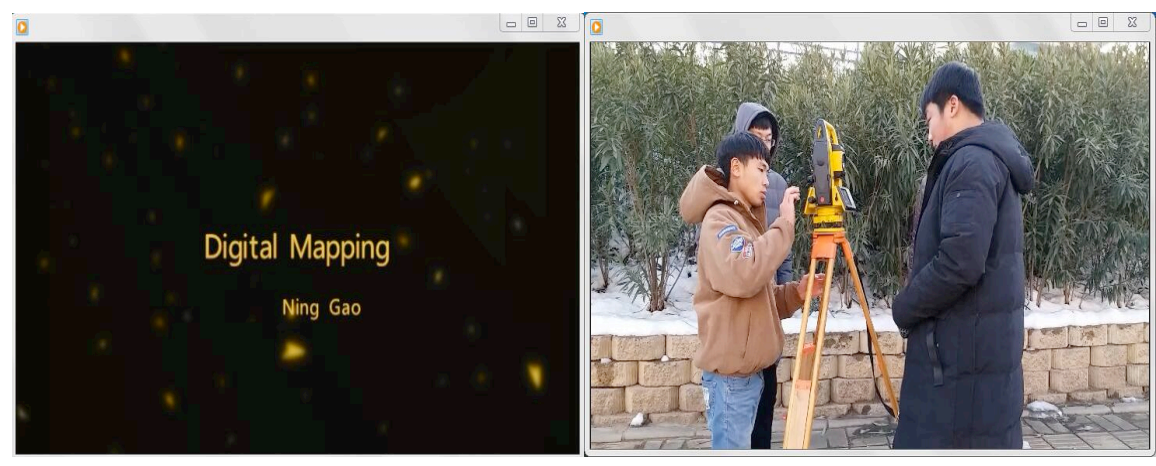

Fig. 5. Micro-video of production internship

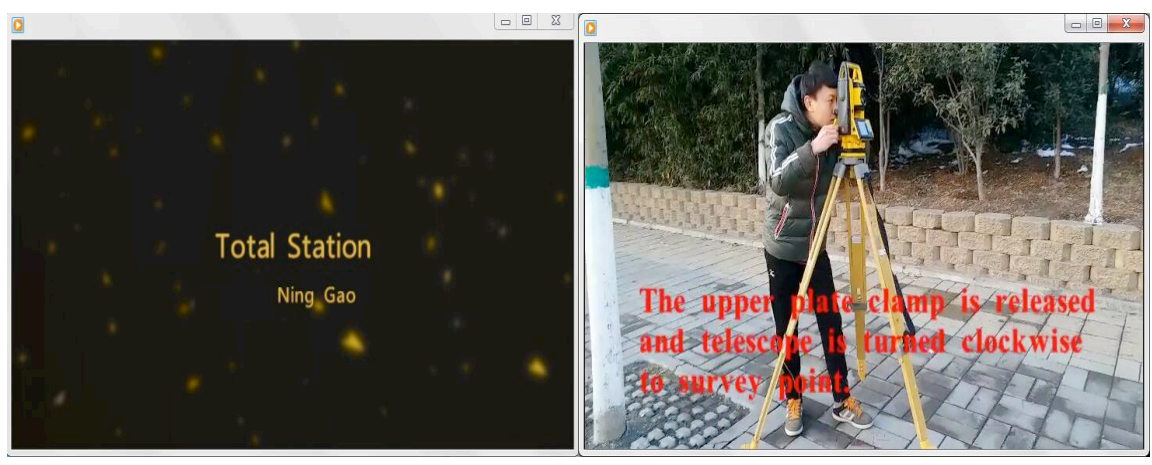

Fig. 6. Subtitle micro-video

The middle subtitle mainly interprets knowledge points that are difficult to understand and provides prompts to key operation steps that can help students to remember them. The end subtitle summarizes and reflects that problems of the micro-video.

Micro-exercise and micro-examination design. To ensure that students learn, interactive technology should be used to realize, exercise, and examine the functions in micro-course. Key attentions are paid to two aspects during the design.

During micro-video playing, questions or linkage of assisting teaching resources pop up. Students have to answer these questions to continue playing the micro-video.

To evaluate the effect of learning man-computer interactive exercises and examinations are offered after watching the micro-video, which requires meticulous design in content and form. The examination has diversified forms of question, including gap filling, calculation, and choice, true-or-false, definition, short-answer, and comprehensive questions. For the convenience of interaction, learners can check their scores and answers after submission and evaluate their learning outcome according to the scores they have obtained. 


\section{Application and analysis of effect}

To comprehend the practice performance of interactive micro-course in digital mapping, the proposed teaching mode is applied to the teaching of digital mapping in the second semester of the academic year 2016-2017.

\subsection{Respondents}

Students of two parallel classes in mapping engineering from the Henan University of Urban Construction are selected as respondents. Classes 0614151 (57 students) 0614152 (57 students) are referred to as ordinary class A and experimental class B, respectively. The proportion of male and female students is generally equal. The two classes are taught by the same teacher and taught with the same content, schedule, and credit hours.

\subsection{Statistical analysis of data}

Data are collected from experimental class B. After implementing the micro-course teaching mode in digital mapping, the interaction module receives the maximum comments, that is, 607, showing an average value of 10.6. Clicks of the micro-video reached 127 clicks/lesson and the reading times are higher than 100 times/lesson. Approximately $95.83 \%$ participated in exercises, examinations, and discussions independently. Particularly, the comprehensive practice videos are browsed by more than 229 times and received more than 115 comments. The videos realized the goal of independent learning effectively. Moreover, these videos not only exhibit considerable effect of teaching and realize individualized and systematic learning of students effectively but also meet the requirements of high interaction, strong experience, and high participation.

\subsection{Questionnaire on the effect of teaching}

Interest on micro-course learning and knowledge points of experimental class $\mathrm{B}$ are surveyed through questionnaires to investigate the effect of the application of interactive micro-course in digital mapping.

The contents of the investigation are as follows: a) investigation on learning interest and interest on knowledge points; and b) key theories, difficult theories, knowledge points that combine theory and practices, instrument operation demonstration, instrument learning, software learning, and engineering cases.

The statistical results are presented in Fig. 7 and Fig.8. Approximately $96.49 \%$ of students are interested in interactive micro-course. Students pay high attention to knowledge points that combined theories and practices, as well as engineering cases. 


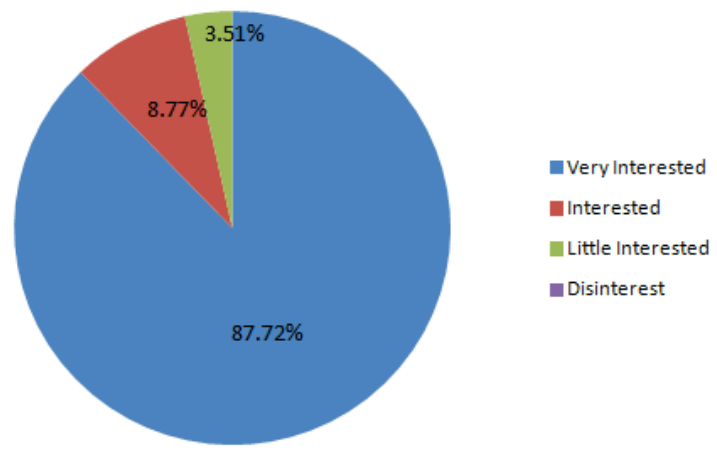

Fig. 7. Questionnaire on learning interest

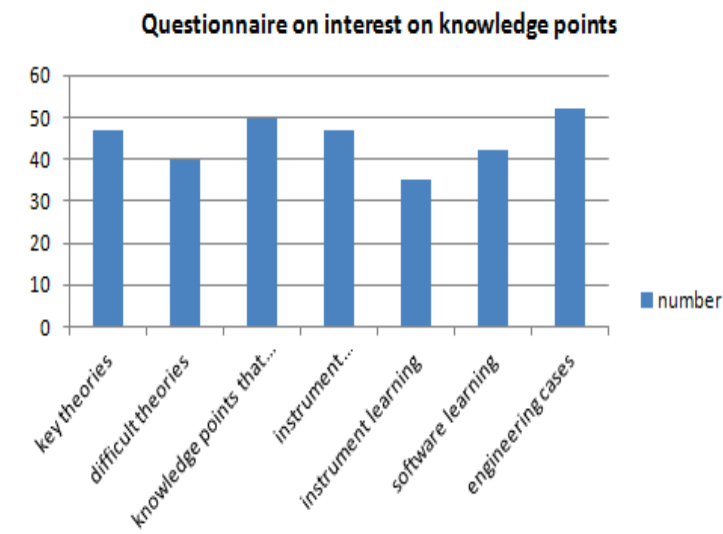

Fig. 8. Questionnaire on interest on knowledge points

\subsection{Contrastive analysis of academic performances between the experimental and the ordinary classes}

A parallel test is conducted to the two classes after they are taught to examine the effect of interactive micro-course teaching mode and evaluate the mastery of students and skilled application of field data acquisition using total station instrument and software mapping. The testing contents included theoretical examination and field training. Field training is conducted in the gymnasium of the Henan University of Urban Construction in the range of $100 \mathrm{~m} * 100 \mathrm{~m}(1: 1000)$. The field training area is shown in Fig. 9, and the statistics of the test results are shown in Table 1.
(a) Gymnasium
(b) Survey control point

Fig. 9. Field training area 
Paper-Construction and Implementation of Teaching Mode for Digital Mapping based on Interactive...

Table 1. Contrastive analysis of academic performances between ordinary and experimental classes

\begin{tabular}{|l|c|c|c|c|}
\hline & \multicolumn{4}{|c|}{ Test contents } \\
\hline \multicolumn{1}{|c|}{ Test class } & $\begin{array}{c}\text { Average academic } \\
\text { score in theory exami- } \\
\text { nation }\end{array}$ & $\begin{array}{c}\text { Field survey data } \\
\text { collection time using } \\
\text { total station }\end{array}$ & $\begin{array}{c}\text { Software map- } \\
\text { ping time }\end{array}$ & $\begin{array}{c}\text { Terrain accu- } \\
\text { racy }\end{array}$ \\
\hline Ordinary class A & 78 & $80 \mathrm{~min}$ & $55 \mathrm{~min}$ & $91 \%$ \\
\hline Experimental class B & 86 & $55 \mathrm{~min}$ & $35 \mathrm{~min}$ & $96 \%$ \\
\hline
\end{tabular}

Table 1 shows that experimental class B achieved better average academic score than ordinary class A, reaching a good standard. In field training, experimental class B takes 25 min shorter to accomplish field data acquisition compared with ordinary class A, and the mapping accuracy is significantly high. With respect to software mapping, experimental class B takes 20 min shorter than class A and the mapping accuracy reaches $96 \%$. These results suggest that the interactive micro-course could actually increase the learning efficiency of students and help them solve actual problems.

\section{Conclusions}

To address the shortcomings of traditional teaching mode for digital mapping, interactive micro-course technology was applied into teaching, from which a new teaching mode was constructed. This mode includes four modules, namely, microcourseware, micro-video, micro-exercise, and micro-examination, and was applied to digital mapping course in mapping engineering in Henan University of Urban Construction. The conclusions are drawn as follows.

1. Interactive micro-course teaching is a new teaching mode that can meet the learning demands of different learners, provide large spaces for free choice, and allow teaching in accordance to aptitude.

2. Interactive micro-course teaching provides students with explicit learning objectives and tasks by issuing micro-courseware, micro-video, micro-exercises, and micro-examination, thereby making complicated engineering cases vivid and objective. This mode of teaching is conducive for the independent learning of students.

3. Interactive micro-course teaching increases the theoretical level and practice ability of students and expands their learning horizons.

This study is merely a preliminary exploration in the application of micro-course in digital mapping. Relevant studies are expected to attract more scholars to provide effective learning resources and environment for learners, and thus facilitate the training of innovative and productive talents. 


\section{References}

[1] Xu Lihua,Li Bing,Zhang Yong,Study on blended experimental teaching based on microcourse and mind mapping,Experimental Technology and Management, 2016, vol.33(12), pp. 180-182.

[2] Koper R,Conditions for effective smart learning environments, Smart Learning Environments, 2014, vol.1(1) , pp. 1-17. https://doi.org/10.1186/s40561-014-0005-4

[3] Shu Chang,Min Lan, Wan Huifang,On College Mathematics Teaching Based on Reverse of Classroom Teachin Mode,Journal of Southwest China Normal University(Natural Science Edition) ,2017, vol.42(9), pp. 196-200.

[4] Gao Caiyun, Wu qiutang,Mobile Teaching of Digital Mapping Based on the WeChat Official Account Admin Platform, International Journal of Emerging Technologies in Learning,2017, vol.12(7), pp. 56-67. https://doi.org/10.3991/ijet.v12i07.7225

[5] Yang Leiduo,Zhou Hui,Research on course construciton and practice of project driven digital mapping technology in higher vocational education, Journal of Guangdong Communication Polytechnic,2016, vol.15(4), pp. 86-90.

[6] Liang Leming,Cao Qiaoqiao,Zhang Baohui, Research on a micro-lecture desigen model through comparavive case study,Open Education Reasearch, 2013, vol. 19(1), pp. 65-73.

[7] Xie Guilan, Analysis offiverlationships between moocs,flipped classoroom ,micro-lecture and micro-video,Education Science, 2015, vol.31(5), pp. 43-46.

[8] Jin Chun,Wang Min,Xu LinLi,Zhang Jia and Lifeng,Design and Practice of Micro-video for College Course, Modern Educational Technology, 2016, vol. 26(3), pp.66-72.

[9] Huang Junsheng, On researching and constructing micro-lecture of laboratory safety education system, Research and exploration in laboratory, 2017, vol. 36(11), pp. 290-293.

[10] Zhang Haining,Sun Jiuyun,Liu Chao and Pang Youzhi, Research on teaching and experiment reform of large scale digital topographic mapping, GNSS World of China,2015, vol. 40(3), pp. 98-100.

[11] LiChuan hua,Zhao Jun,Zhang Changcheng and Lu Lintao, Digital Mapping Mode Based on Mobile Communication, Journal of Geomatics Science andTechnology,2011,vol. 28(2), pp. 94-97.

[12] Gao Ning,Gao Caiyun.The use of comprehensive practical skill competitions in cultivating the innovative abilities of surveying undergraduates. World Transactions on Engineering and Technology Education, 2015, vol.13(4), pp. 469-473.

[13] Yu Daijun,zheng Pingyuan, Yang Ronghao and Huang Qiang,Investiagtion on practice of suvveying based on semi-digitized topographic mapping, Science of Surveying and Mapping,2015, vol.40(8), pp. 97-99.

\section{$7 \quad$ Authors}

Ning Gao is an associate professor in School of Geomatics \& Urban Information, Henan University of Urban Construction, Pingdingshan 467036, China (e-mail: gaoninghaoyun@163.com).

Article submitted 13 October 2017. Resubmitted 14 December 2017. Final acceptance 04 February 2018. Final version published as submitted by the authors. 